\title{
Long-term prognostic analysis of early interventional therapy for lower extremity deep venous thrombosis
}

\author{
QIANG LI ${ }^{1}$, ZONGXUE YU ${ }^{2}$, JINJUN WANG ${ }^{1}$, XIAO CHEN $^{1}$ and LIN LI ${ }^{1}$ \\ ${ }^{1}$ Department of Vascular Surgery, The Affiliated Qingdao Hiser Hospital of Qingdao University; \\ ${ }^{2}$ Department of Internal Medicine, The Third People's Hospital of Qingdao, Qingdao, Shandong 266033, P.R. China
}

Received July 4, 2016; Accepted September 20, 2016

DOI: 10.3892/etm.2016.3812

\begin{abstract}
The aim of the present study was to observe the long-term prognostic value of early interventional therapy for lower extremity deep venous thrombosis (LDVT). In total, 85 patients diagnosed with LDVT for the first time were consecutively selected (identified course of disease was $<3$ months), and were divided into the control group with 43 cases and the observation group with 42 cases according to different therapeutic methods. The control group received anticoagulation therapy and thrombolysis, or integrated surgical thrombectomy, a conventional open operation, while the observation group received comprehensive treatment, combining endovascular catheter-directed thrombolysis and thrombectomy. The therapeutic effects were compared. After treatment, the differences in circumference of the thigh and shank between the affected and unaffected extremities, and vein dysfunction score of the two groups were decreased compared with before treatment. In addition, the above indexes of the observation group were significantly lower than in the control group $(\mathrm{P}<0.05)$. The clinical effective rate and effective extent of the observation group were higher than those of the control group, and the differences were statistically significant $(\mathrm{P}<0.05)$. The occurrence rate of post-thrombotic syndrome in the observation group was lower than that of the control group, and there was no difference in comparison of grading. The recurrence rate and restenosis rate of the observation group were lower than in the control group, while the patency rate of the observation group was higher than that of the control group, and the differences were statistically significant $(\mathrm{P}<0.05)$. In conclusion, early catheter-directed invention of thrombolysis with thrombectomy for LDVT has good clinical effect in the short-term and long-term.
\end{abstract}

Correspondence to: Dr Qiang Li, Department of Vascular Surgery, The Affiliated Qingdao Hiser Hospital of Qingdao University, 4 Renmin Road, Qingdao, Shandong 266033, P.R. China E-mail: 1130149004chengc@163.com

Key words: endovascular interventional treatment, deep venous thrombosis, post-thrombotic syndrome, thrombolysis, anticoagulation

\section{Introduction}

Lower extremity deep venous thrombosis (LDVT) is caused by various factors. Blood abnormally pools in the deep veins, forming a thrombus and the vena cava is partially or completely blocked, leading to a block of blood return $(1,2)$. The high-risk population are mostly those with severe injury, in gestation, with peripheral vessel lesions and confined to bed for prolonged periods of time (3). If patients are not treated as early as possible, their affected extremities may appear with complete or partial dysfunction. In severe cases, acute pulmonary embolism (PE) caused by dislodging of a clot may occur, and most of the patients may develop post-thrombotic syndrome (PTS) (4).

As endovascular intervention technology has improved, early endovascular intervention has become an important supplementary method for thrombolysis, anticoagulation therapy, and surgical thrombectomy (5). Previous findings have shown that interventional therapy has many advantages, such as causing small trauma, is safe and reliable, and is comparable and possibly superior to the effect of medication alone or the combined effect of medicine and surgery $(6,7)$. Due to different sample sizes and follow-up times, the effects of interventional therapy were different $(8,9)$. Whether early intervention of thrombolysis is an effective first-line treatment for LDVT is not yet known.

In the present study, we analyzed the effect of early endovascular intervention on LDVT, aiming to provide a reference for treatment options.

\section{Patients and methods}

Patients. Eighty-five patients diagnosed with LDVT for the first time between January 2013 and January 2016 at the Affiliated Qingdao Hiser Hospital of Qingdao University, were consecutively selected. The identified course of disease was $<3$ months as confirmed by lower extremity venous ultrasonography or venography. The exclusion criteria included: Organized thrombi; complications with other lower extremity venous lesions, such as phlebophlogosis, and absence of venous valves in the lower extremities; vena cava thrombosis; acute PE; lower extremity venous malformation that could not be punctured; contrast agent allergy; complications with underlying diseases, such as of the heart, liver, kidney, lung, 
Table I. Comparison of baseline parameters of the two groups.

\begin{tabular}{|c|c|c|c|c|}
\hline Parameters & $\begin{array}{l}\text { Control } \\
\text { group } \\
(n=43)\end{array}$ & $\begin{array}{l}\text { Observation } \\
\text { group }(n=42)\end{array}$ & $\mathrm{t} / \chi^{2}$ & P-value \\
\hline $\mathrm{M} / \mathrm{F}$ & $28 / 15$ & $30 / 12$ & 0.391 & 0.532 \\
\hline Age (years) & $46.8 \pm 12.3$ & $47.5 \pm 13.6$ & 0.237 & 0.628 \\
\hline $\begin{array}{l}\text { Average duration } \\
\text { (weeks) }\end{array}$ & $4.8 \pm 2.3$ & $5.0 \pm 2.5$ & 0.266 & 0.613 \\
\hline $\begin{array}{l}\text { Central type } \\
\text { thrombus }\end{array}$ & $31(72.1)$ & $34(81.0)$ & 0.927 & 0.336 \\
\hline $\begin{array}{l}\text { Mixed type } \\
\text { thrombus }\end{array}$ & $12(27.9)$ & $8(19.0)$ & & \\
\hline $\begin{array}{l}\text { Average length of } \\
\text { thrombus }(\mathrm{cm})\end{array}$ & $2.6 \pm 0.9$ & $2.7 \pm 0.8$ & 0.324 & 0.637 \\
\hline $\begin{array}{l}\text { Average diameter } \\
(\mathrm{mm})\end{array}$ & $5.3 \pm 2.6$ & $5.2 \pm 2.3$ & 0.421 & 0.456 \\
\hline Traumatism & $18(41.9)$ & $17(40.5)$ & 0.144 & 0.931 \\
\hline Postoperation & $12(27.9)$ & $13(31.0)$ & & \\
\hline $\begin{array}{l}\text { Long-term } \\
\text { bedridden }\end{array}$ & $16(37.2)$ & $18(42.9)$ & & \\
\hline
\end{tabular}

M, male; F, female.

brain and other organs; and secondary to other primary causes such as field activity, pregnancy, and early postoperative fracture.

Approval for the study was obtained by the Ethics Committee of the Affiliated Qingdao Hiser Hospital of Qingdao University. Written informed consent from patients or their families was obtained. The patients were divided into the control group with 43 cases and the observation group with 42 cases, according to the different therapeutic methods. The baseline parameters of the patients from the two groups was comparable (Table I).

Research methods. After admission, the patients from the two groups underwent prostration with the affected extremity raised up $15-30^{\circ}$ to improve microcirculation. Patients in the control group received medicine alone or medicine combined with conventional open surgery for thrombus extraction. The anticoagulant drugs used were subcutaneous injection of $100 \mathrm{IU} / \mathrm{kg}$ low molecular heparin sodium, once every $12 \mathrm{~h}$, and after 5 days, warfarin sodium tablet thrombolysis treatment was adopted at $2.5 \mathrm{mg} / \mathrm{day}$. On the 8th day, low molecular heparin sodium was stopped, and patients received oral warfarin sodium tablets at $2.5 \mathrm{mg}$ /day for at least 6 months. Close monitoring of coagulation function was performed during treatment.

The observation group received endovascular interventional treatment in the supine position, with a venipuncture approach through the unaffected side to insert a catheter sheath after local anesthesia, to observe if there was stenosis and thrombosis by inferior vena cava angiography. An inferior vena cava filter was placed, and the catheter was inserted into the iliofemoral vein of the affected side with assistance of a guide wire. Thrombus accumulation of the proximal part was
Table II. PTS grading.

\begin{tabular}{lccc}
\hline Signs and symptoms & $\begin{array}{c}\text { Class I } \\
\text { (light) }\end{array}$ & $\begin{array}{c}\text { Class II } \\
\text { (intermediate) }\end{array}$ & $\begin{array}{c}\text { Class III } \\
\text { (severe) }\end{array}$ \\
\hline Painful symptoms & 1 & 2 & 3 \\
Muscle spasm & 1 & 2 & 3 \\
Heaviness & 1 & 2 & 3 \\
Skin itch & 1 & 2 & 3 \\
Paresthesia & 1 & 2 & 3 \\
Pretibial myxedema & 1 & 2 & 3 \\
Hyperpigmentation & 1 & 2 & 3 \\
Red skin color & 1 & 2 & 3 \\
Skin sclerosis & 1 & 2 & 3 \\
Gastrocnemius & 1 & 2 & 3 \\
muscle pain & & 2 & 3 \\
Varicosity & 1 & No & Yes \\
Venous ulceration & No & & \\
\hline
\end{tabular}

PTS, post-thrombotic syndrome.

monitored by radiography and thrombolysis catheters were replaced in time to fix the side holes of the head-end fully into the thrombus. Urokinase (50 WU/day) was pumped through the catheter for $24 \mathrm{~h}$, which could have been integrated with thrombectomy. According to the state of thrombolysis demonstrated by venography after 1 week, the hole on the side of the catheter head was adjusted with a coagulation function monitor and the iliac vein was treated with stent implantation or angioplasty.

Observational indexes and evaluation methods. The difference in circumference of the thigh and shank between the affected and unaffected extremities, and vein dysfunction score (VDS) of the two groups were analyzed and compared with the values before treatment. The standards for VDS were: No pain but with some symptoms, including skin itch and muscle spasm was assigned 0 points; clinical symptoms, but with normal daily activities and no need for elastic webbing support treatment was assigned 1 point; clinical symptoms, with need for elastic webbing support and raised affected extremity working normally was assigned 2 points; clinical symptoms, with need for elastic webbing support and raised affected extremity working abnormally was assigned 3 points.

Clinical efficiency rates were compared. The evaluation standards for therapeutic effect were: Smooth and unobstructed vein wall detected by color Doppler ultrasound with no thrombus was considered class I recovery (excellent); smooth but rough vein wall detected by color Doppler ultrasound, with blood vessel diameter $>70 \%$ was considered class II (good); thrombus remains shown by color Doppler ultrasound, with blood vessel diameter $\leq 70 \%$ was considered class III (effective); symptoms did not improve or were worse and the deep vein was obstructed was considered class VI (invalid).

The incidence of PTS during the perioperative period and follow-up was compared, applying the Villalta score to mark 
Table III. Comparison of difference in perimeter of thigh and shank between affected and unaffected extremities, and VDS.

\begin{tabular}{|c|c|c|c|c|c|c|}
\hline \multirow{2}{*}{ Groups } & \multicolumn{2}{|c|}{$\begin{array}{c}\text { Difference in perimeter } \\
\text { of thigh }(\mathrm{cm})\end{array}$} & \multicolumn{2}{|c|}{$\begin{array}{l}\text { Difference in perimeter } \\
\text { of shank }(\mathrm{cm})\end{array}$} & \multicolumn{2}{|c|}{ VDS (points) } \\
\hline & Before treatment & After treatment & Before treatment & After treatment & Before treatment & After treatment \\
\hline Control & $3.63 \pm 0.8$ & $2.15 \pm 1.02$ & $1.95 \pm 0.36$ & $1.26 \pm 0.33$ & $2.2 \pm 0.6$ & $1.3 \pm 0.5$ \\
\hline Observation & $3.74 \pm 0.9$ & $0.86 \pm 0.24$ & $2.01 \pm 0.44$ & $0.53 \pm 0.15$ & $2.1 \pm 0.5$ & $0.6 \pm 0.2$ \\
\hline t-test & 0.234 & 5.928 & 0.326 & 6.082 & 0.993 & 5.483 \\
\hline P-value & 0.727 & 0.016 & 0.528 & 0.013 & 0.124 & 0.019 \\
\hline
\end{tabular}

VDS, vein dysfunction score.

Table IV. Comparison of clinical effective rate and PTS occurrence rate [n (\%)].

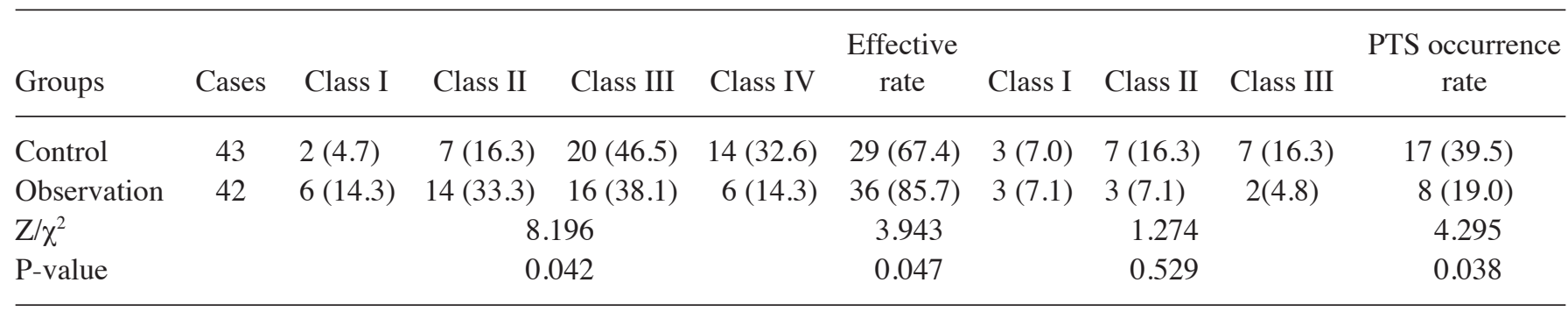

PTS, post-thrombotic syndrome.

the level of PTS from class I-III, and the score from no symptoms to severe (0-3 points) (Table II).

The follow-up rates of recurrence, restenosis, and unobstruction were compared. The rate of unobstruction referred to lower extremity deep veins, and the inferior vena cava system (common femoral veins, inferior vena cava segment, vena iliaca externa, common iliac vein, popliteal vein, and upper and lower segment of the superficial femoral vein). Rate of unobstruction was graded as follows: Completely unobstructed was assigned 0 points; partially unobstructed was assigned 1 point; thrombus was found with obstruction was assigned 2 points. The score for rate of unobstruction was the sum of scores for seven vein segments. Rate of vein unobstruction $=$ score (before treatment - after treatment) score/score before treatment $\times 100 \%$.

Statistical analysis. SPSS 19.0 software was used for data analysis (IBM SPSS, Armonk, NY, USA). Measurement data were presented as mean \pm standard deviation. Comparisons between groups were by independent sample t-test. Countable data are presented as rate, and comparisons between groups were by $\chi^{2}$ test. For ranked data, non-parametric rank-sum test was adopted. $\mathrm{P}<0.05$ was considered to indicate a statistically significant difference.

\section{Results}

Comparison of difference of circumference of the thigh and shank between affected and unaffected extremities, and VDS. After treatment, the difference in circumference of the thigh and shank between the affected and unaffected extremities,
Table V. Comparison of follow-up recurrence rate, restenosis rate and patency rate $[\mathrm{n}(\%)]$.

\begin{tabular}{lcccc}
\hline Groups & Cases & $\begin{array}{c}\text { Recurrence } \\
\text { rate }\end{array}$ & $\begin{array}{c}\text { Restenosis } \\
\text { rate }\end{array}$ & $\begin{array}{c}\text { Patency } \\
\text { rate }\end{array}$ \\
\hline Control & 43 & $10(23.3)$ & $15(34.9)$ & $25(58.1)$ \\
Observation & 42 & $3(7.1)$ & $6(14.3)$ & $33(78.6)$ \\
$\chi^{2}$ & & 4.258 & 5.143 & 4.092 \\
P-value & & 0.039 & 0.023 & 0.043 \\
\hline
\end{tabular}

and VDS of the two groups decreased compared with before treatment. The differences were significantly lower in the observation group compared with the control group $(\mathrm{P}<0.05)$ (Table III).

Comparison of clinical effective rate and PTS occurrence rate. The clinical effective rate and effective rate of the observation group was significantly higher than that of the control group $(\mathrm{P}<0.05)$. The follow-up period of the two groups was 3-35 months, with median time of 18.5 months. The occurrence rate of PTS in the observation group was lower than that of the control group $(\mathrm{P}<0.05)$ (Table IV).

Comparison of follow-up rates of recurrence, restenosis, and patency. The recurrence rate and restenosis rate of the observation group were lower than in the control group, while the patency rate of the observation group was higher than that of 
the control group, and the differences were statistically significant $(\mathrm{P}<0.05)$ (Table V).

\section{Discussion}

The treatment of LDVT primarily includes early anticoagulation, thrombectomy, and thrombolysis. However, the PTS occurrence rate for long-term prognosis is unsatisfactory. Catheter-directed thrombolysis is a new form of interventional therapy, which can transport thrombolytic drugs (i.e., urokinase) to the thrombus through the thrombolytic catheter, thereby reducing the metabolism of urokinase which occurs during the conventional transport processes to promote high drug concentration. This results in an increase of drug utilization rate (10). The head of the thrombolysis catheter has many holes on different sides and thrombolytic drugs can spray from these holes via micro-pump, leading to increased contact between drugs and the thrombus, so that the number of activated plasminogen molecules in the thrombus increases, which can maintain the local drug concentration in the thrombus for a long time (11). Similarly, it can decrease the degree of thrombus organization, which is beneficial for complete dissolution of the thrombus (12).

PTS is a very common complication in the long-term, and is a phenomenon that occurs during the recovery phase of deep veins after thrombosis. Blood countercurrent following recanalization results in high pressure and congestion of the vein, leading to shallow varicose veins, limb swelling pain, pigmentation, and skin ulcers (13). Whether the deep vein is unobstructed or not directly affects prognosis, especially for the thin iliac vein wall, with poor elasticity that easily loses its shape when pressed. Additionally, reocclusion and restenosis can cause recurrence of deep venous thrombosis (14). Stent implantation by comprehensive interventional treatment can maintain blood flow velocity and volume to guarantee long-term rate of patency, thus reducing the degree and incidence of PTS, which has great significance for the long-term prognosis of LDVT $(15,16)$.

The present study has shown that the difference in circumference of the thigh and shank between the affected and unaffected extremities, and VDS of the observation group decreased significantly after treatment. The clinical effective rate and effective extent of the observation group increased. PTS occurrence decreased and the rates of recurrence and restenosis of the observation group decreased significantly. The rate of patency increased as well. The differences were statistically significant. In conclusion, early invention of thrombolysis combined with thrombectomy for deep venous thrombosis has good clinical effect in the short-term and long-term, with reduction of PTS. The combined treatment is safe, effective, and worthy of clinical promotion.

\section{References}

1. Durbec O, Viviand X, Potie F, Vialet R and Martin C: Lower extremity deep vein thrombosis: A prospective, randomized, controlled trial in comatose or sedated patients undergoing femoral vein catheterization. Crit Care Med 25: 1982-1985, 1997.

2. Quinlan DJ, Alikhan R, Gishen P and Sidhu PS: Variations in lower limb venous anatomy: Implications for US diagnosis of deep vein thrombosis. Radiology 228: 443-448, 2003.

3. Roupie AL, Dossier A, Goulenok T, Perozziello A, Papo T and Sacre K: First venous thromboembolism in admitted patients younger than 50 years old. Eur J Intern Med 2323: 14-15, 2016.

4. González Vázquez L, Santos Armentía E and de la Fuente Aguado J: Post-thrombotic syndrome. Rev Clin Esp 18: 16-17, 2016 (In Spanish).

5. Saroukhani A, Ravari H and Pezeshki Rad M: Effects of intravenous and catheter directed thrombolytic therapy with recombinant tissue plasminogen activator (Alteplase) in non-traumatic acute limb ischemia; a randomized double-blind clinical trial. Bull Emerg Trauma 3: 86-92, 2015.

6. Sag S, Nas OF, Kaderli AA, Ozdemir B, Baran I, Erdoğan C, Gullulu S, Hakyemez B and Aydinlar A: Catheter-directed ultrasound-accelerated thrombolysis may be life-saving in patients with massive pulmonary embolism after failed systemic thrombolysis. J Thromb Thrombolysis 29: 12-13, 2016.

7. Dong JY, Zhu QH, Luo MH, Zhou CY, Huang W and Yu XF: Clinical significance of monitoring coagulation- and fibrinolysis-related indexes during catheter-directed thrombolysis for acute lower-extremity deep venous thrombosis. Nan Fang Yi Ke Da Xue Xue Bao 36: 588-591, 2016 (In Chinese).

8. Gorek Dilektasli A, Demirdogen Cetinoglu E, Acet NA, Erdogan C, Ursavas A, Ozkaya G, Coskun F, Karadag M and Ege E: Catheter-directed therapy in acute pulmonary embolism with right ventricular dysfunction: a promising modality to provide early hemodynamic recovery. Med Sci Monit 22: 1265-1273, 2016.

9. Sundar G, Keshava SN, Moses V, Chiramel GK, Ahmed M, Mammen S, Aggarwal S and Stephen E: Outcomes of catheter-directed treatment of lower extremity deep vein thrombosis of patients presenting to a tertiary care hospital. Indian J Radiol Imaging 26: 73-80, 2016.

10. Yoo JW, Choi HC, Lee SJ, Cho YJ, Lee JD and Kim HC: Comparison between systemic and catheter thrombolysis in patients with pulmonary embolism. Am J Emerg Med 34: 985-988, 2016.

11. Jiang K, Li XQ, Sang HF, Qian AM, Rong JJ and Li CL: Mid-term outcome of endovascular treatment for acute lower extremity deep venous thrombosis. Phlebology 27: 54-55, 2016.

12. Sharma V, Goldberg HD, Zubkus D, Shears LL and Kaczorowski DJ: Successful management of cardiac arrest due to pulmonary embolus using extracorporeal membrane oxygenation and ultrasound-accelerated catheter-directed thrombolysis. Ann Thorac Surg 101: e107-e109, 2016.

13. Siddiqui NA, Sophie Z, Zafar F, Soares D and Naz I: Predictors for the development of post-thrombotic syndrome in patients with primary lower limb deep venous thrombosis: a case-control study. Vascular 15: 65-66, 2016.

14. Burgstaller JM, Steurer J, Held U and Amann-Vesti B: Efficacy of compression stockings in preventing post-thrombotic syndrome in patients with deep venous thrombosis: a systematic review and meta-analysis. Vasa 45: 141-147, 2016.

15. Ten Cate-Hoek A: Efficacy of compression for the prevention of post-thrombotic syndrome: an unsolved clinical conundrum Comment on Burgstaller et al, p141-147. Vasa 45: 85-86, 2016.

16. Stevenson A and Gándara E: Statins for the prevention of post-thrombotic syndrome in patients with deep vein thrombosis. Comment on San Norberto et al, p133-140. Vasa 45: 83-84, 2016. 